\title{
The Effect of Content and Physical Properties of Affective Pictures on Emotional Responses
}

\author{
Juan Pedro Sánchez-Navarro, José María Martínez-Selva, \\ Francisco Román, and Ginesa Torrente \\ Universidad de Murcia
}

\begin{abstract}
The aim of this research was to study the influence of both the emotional content and the physical characteristics of affective stimuli on the psychophysiological, behavioral and cognitive indexes of the emotional response. We selected 54 pictures from the IAPS, depicting unpleasant, neutral, and pleasant contents, and used two picture sizes as experimental conditions $(120 \times 90 \mathrm{~cm}$ and $52 \times 42 \mathrm{~cm})$. Sixty-one subjects were randomly assigned to each experimental condition. We recorded the startle blink reflex, skin conductance response, heart rate, free viewing time, and picture valence and arousal ratings. In line with previous research (e.g., Bradley, Codispoti, Cuthbert, \& Lang, 2001), our data showed an effect of the affective content on all the measurements recorded. Importantly, effects of the size of the affective pictures on emotional responses were not found, indicating that the emotional content is more important than the formal properties of the stimuli in evoking the emotional response.
\end{abstract}

Keywords: emotion, picture size, startle blink reflex, skin conductance response, heart rate

\begin{abstract}
El objetivo de esta investigación fue estudiar la influencia del contenido emocional y de las características físicas de los estímulos afectivos sobre los índices psicofisiológicos, conductuales y cognitivos de la respuesta emocional. Seleccionamos 54 imágenes del IAPS, representando contenidos desagradables, neutros y agradables y usamos dos tamaños de imagen como condiciones experimentales $(120 \times 90 \mathrm{~cm}$ y $52 \times 42 \mathrm{~cm})$. Los 61 sujetos que conformaban la muestra experimental se asignaron de forma aleatoria a cada condición experimental. Registramos el parpadeo reflejo de sobresalto, la respuesta de conductancia de la piel, la frecuencia cardiaca, el tiempo de visión y las estimaciones de valencia afectiva y arousal de las imágenes. De acuerdo con la investigación previa (p. ej., Bradley, Codispoti, Cuthbert y Lang, 2001), nuestros datos mostraron un efecto del contenido afectivo en todas las medidas registradas. Nuestros resultados no mostraron, sin embargo, efectos del tamaño de las imágenes afectivas sobre ninguna de las medidas registradas, lo que indica que el contenido afectivo es más importante que las propiedades formales de los estímulos para provocar respuestas emocionales.

Palabras clave: emoción, tamaño de la imagen, parpadeo reflejo de sobresalto, respuesta de conductancia de la piel, frecuencia cardiaca
\end{abstract}

Correspondence concerning this article should be addressed to J.P. Sánchez-Navarro, Departamento de Anatomía Humana y Psicobiología, Facultad de Psicología, Universidad de Murcia, Campus de Espinardo, 30100 Murcia (Spain). Phone: 968367 707. E-mail: jpedro@ um.es. 
The aim of this research was to determine whether emotional responses depend on the content of the affective stimuli and whether the formal properties of the stimuli, such as size, exert any influence on the psychophysiological, behavioral, and cognitive indices of this response.

The study of the formal properties of the visual stimuli used to generate emotions has important consequences in social psychology, for example, communication, persuasion, and attitude change (Cacioppo \& Sandman, 1981; Detenber \& Reeves, 1996), in clinical psychology, for instance, phobia treatment (Mühlberger, Herrmann, Wiedemann, Ellgring, \& Pauli, 2001; Wald \& Taylor, 2000), and in experimental psychology. From an experimental perspective, however, this is not usually considered a relevant methodological issue for emotion-related research that employs pictures to elicit emotional responses. For example, researchers use different formats of visual stimuli to evoke emotions, such as size (e.g., Globisch, Hamm, Esteves, \& Öhman, 1999; Lang, Greenwald, Bradley, \& Hamm, 1993; Larson, Ruffalo, Nietert, \& Davidson, 2000), color (Bradley, Codispoti, Cuthbert, \& Lang, 2001; Grimshaw, Bulman-Fleming, \& Ngo, 2004; Rossignol, Philippot, Douilliez, Crommelinck, \& Campanella, 2005), or movement (Christie \& Friedman, 2004; Gomez, Zimmermann, Guttormsen-Schär, \& Danuser, 2005; Jansen \& Frijda, 1994).

Multiple responses-facial expression, autonomic reactivity, motor responses, and affective evaluations-are involved in emotional behavior (Lang, 1968, 1984). Pictures resemble the real object and events that they represent and they may activate the cognitive representations related to emotional responses. Affective processing activates facial expression and may cause autonomic responses like those evoked by the actual emotional stimuli (Lang et al., 1993). Hence, the more similar the pictures are to the real object or situation, the closer the elicited emotional reactions should be. In this line, some authors have found that the formal properties of visual stimuli can influence cognitive processing and the emotional responses evoked by them (Detenber \& Reeves, 1996; Simons, Detenber, Reiss, \& Shults, 2000; Simons, Detenber, Roedema, \& Reiss, 1999). Detenber and Reeves found that several parameters of the picture format, such as size and movement, had an influence on the subjective evaluation of the affective pictures. Large pictures were rated as more arousing than small ones, but these authors found no differences in the ratings of the affective valence. They concluded that this arousing effect of large pictures was independent of the content and could be explained because a large picture would favor responding to the picture as if it were real.

In a later study, Reeves, Lang, Kim, and Tatar (1999) included the heart rate (HR) elicited by the pictures as a psychophysiological index related to affective valence. However, this might not be a specific index of the emotional response because some authors have found a relationship between HR change and both affective valence ratings (e.g.,
Greenwald, Cook, \& Lang, 1989), and arousal ratings (e.g., Lang et al., 1993; Sánchez-Navarro, Martínez-Selva, \& Román, 2005). Hence, we decided to employ a psychophysiological measure more closely related to emotion-the affective modulation of the startle blink reflex-together with other autonomic (electrodermal activity and HR change), behavioral (viewing time), and subjective (affective valence and arousal ratings) responses.

An extensive set of studies has shown a startle blink reflex modulation related to the affective content of the stimuli, with greater magnitudes when subjects view unpleasant pictures, and lower ones when they view pleasant pictures (e.g., Bradley, Cuthbert, \& Lang, 1990; Bradley, Codispoti, Cuthbert, et al., 2001; Cuthbert, Bradley, \& Lang, 1996; Vila et al., 2003; Vrana, Spence, \& Lang, 1988). Picture viewing also evokes an initial HR deceleration and final HR acceleration, which are greater when pictures are unpleasant (Bradley et al., 1990; Lang et al., 1993). However, other studies have also found a relationship between HR and the arousal elicited by the pictures (e.g., Lang et al., 1993; Sánchez-Navarro et al., 2005). In turn, skin conductance response (SCR) depends on the arousal level of the affective stimuli, with the most arousing pictures evoking the largest SCRs (e.g., Bradley et al., 1990; Lang et al., 1993).

Because previous research has shown startle reflex modulation to be a function of the affective valence of the pictures (e.g., Bradley et al., 1990; Vrana et al., 1988), independently of some formal picture features such as color (Bradley, Codispoti, Cuthbert, et al., 2001), we expected that the startle reflex modulation would depend on the content of the pictures rather than on the size. Thus, in both conditions, we expected to find enhanced responses to unpleasant pictures and inhibited responses to pleasant ones, when compared to neutral ones. Skin conductance responses were expected to depend on picture size, with higher responses to larger stimuli, as previous research has shown (e.g., Reeves et al., 1999). In addition, a content effect would be expected in both experimental conditions, with larger SCRs elicited by arousing pictures (pleasant and unpleasant) than those evoked by non-arousing ones (neutral). We also expected to find a greater HR initial deceleration and final acceleration in response to large pictures than to small ones, showing an attentional effect of the picture size. Furthermore, we expected that unpleasant pictures would evoke the greatest HR change in both conditions. From the work of Detenber and Reeves (1996), we expected that whereas affective valence ratings would not show differences depending on the size of the stimuli, arousal ratings should show differences as a function of picture size, with subjects rating large pictures as more arousing than small ones. Following the results of Reeves et al., indicating that large pictures demand greater attention than small ones, we also expected longer viewing times for large pictures than for small ones in a 
free viewing task. In addition, an effect of the content was also expected, with subjects viewing high arousing pictures for longer times.

\section{Method}

\section{Participants}

The experimental sample was made up of 61 undergraduates, 23 men and 38 women, with a mean age of $19.75(S D=2.95)$, recruited through class advertisements from the School of Psychology of the University of Murcia. Participants were randomly assigned to one of the two experimental conditions (small pictures vs. large pictures), resulting in 31 participants in the large size condition and 30 in the small one.

The data of 4 participants were unavailable for startle blink magnitude $(n=57)$. The SCR data of 6 participants were discarded from statistical analysis due to a low rate of responses $(n=55)$, and 6 participants were also discarded from HR due to the presence of artifacts in their recordings $(n=55)$.

\section{Materials and Stimuli}

Fifty-four color pictures were selected from the International Affective Picture System (IAPS; CESEANIHM, 1999) ${ }^{1}$. According to the normative data for the Spanish population (Moltó et al., 1999; Vila et al., 2001), 18 pictures were unpleasant, 18 were neutral, and 18 were pleasant. Pleasant and unpleasant pictures did not differ in arousal level $(>6)$, whereas the neutral ones presented a low arousal level $(<3.5)$.

The pictures were arranged in six blocks of nine pictures each, so that three pictures of each affective valence type were present in each block. Three picture presentation orders were constructed so that each picture appeared across participants with the same probability at different moments of the experimental task. Participants were randomly assigned to one of the presentation orders in each experimental condition.

Each picture was presented for $6 \mathrm{~s}$ (with random intertrial intervals of 18-30 s), and picture offset was a blank screen. The acoustic startle probes were presented for two of the three pictures of each affective category per block, at a random time between 3500 and $4500 \mathrm{~ms}$ after picture onset. An acoustic probe was also delivered in two intertrial intervals per block in order to ensure unpredictability.
Pictures were generated with a PC-computer. Large pictures were displayed on a screen (maximum viewing area of $120 \times 90 \mathrm{~cm}$ ) through a Mitsubishi LVP-S50UX picture projector, and small pictures were displayed on a Grundig ST70-282/8 television (maximum viewing area of $52 \times 42$ $\mathrm{cm}$ ). In both conditions, image resolution was $640 \times 480$ pixels.

The acoustic startle probe consisted of a 50-ms 105$\mathrm{dB}(\mathrm{A})$ burst of white noise $(20 \mathrm{~Hz}-20 \mathrm{KHz})$ with instantaneous rise time, presented binaurally through headphones, and generated by a custom-made noise stimulator from the facilities of the University of Murcia. This stimulator was controlled by the computer that presented the pictures and facilitated the parameter programming of both the acoustic and visual stimuli. The intensity of the acoustic stimulus was previously calibrated using a Brüel \& Kjaer artificial earphone (Type 4153) and a sound level meter (Type 2231).

\section{Physiological Recording}

Acquisition, amplification, and filtering of the physiological signals were carried out by an ADInstruments PowerLab 8/sp data acquisition system, which converted analogical signals to digital signals by means of a 16-bit $\mathrm{A} / \mathrm{D}$ converter.

Startle blink reflex was measured by recording EMG activity from the orbicularis oculi muscle beneath the left eye, using a bipolar placement of 4-mm Ag/ $\mathrm{AgCl}$ surface electrodes (Fridlund \& Cacioppo, 1986). The raw EMG signal was amplified and frequencies below $60 \mathrm{~Hz}$ and above $500 \mathrm{~Hz}$ were filtered out using an ADInstruments BioAmp-ML132 bioamplifier. The raw signal was fullwave rectified and integrated off-line with a time constant of $15 \mathrm{~ms}$.

Skin conductance response was obtained by the bipolar placement of 7-mm Ag/AgCl surface electrodes, filled with isotonic electrolytic paste, on the thenar (C6) and hipothenar (C8) eminences of the non-dominant hand surface (Fowles et al., 1981). This signal was amplified and filtered out to detect activity in the 0-100 microSiemens range, using a Cibertec Biosig-CP1 module

Lead I electrocardiogram was recorded using 7-mm $\mathrm{Ag} / \mathrm{AgCl}$ surface electrodes filled with hypertonic electrolyte paste. The signal was amplified with a $1-\mathrm{mV}$ range, and filtered out with cut-offs below $0.3 \mathrm{~Hz}$ and above $100 \mathrm{~Hz}$, using an ADInstruments BioAmp-ML132 bioamplifier.

All physiological signals were digitized continuously at $1000 \mathrm{~Hz}$ for the entire experimental session.

1 Pictures selected from the International Affective Picture System: unpleasant (3100, 3102, 3150, 3170, 3350, 3400, 3500, 6230, $6242,6260,6313,6350,6360,6530,6570,6821,9050,9920)$; neutral $(7002,7004,7006,7009,7010,7025,7030,7035,7040,7060$, $7080,7090,7150,7185,7217,7224,7233,7235)$; and pleasant $(4652,4658,4659,4664,4669,4670,4672,4800,5621,5623,5626$, $5628,5629,8030,8180,8370,8490,8496)$. 


\section{Procedure}

The study was conducted in the Laboratory of Human Psychophysiology of the University of Murcia, in a darkened, sound-attenuated chamber $(3.06 \times 2.02 \times 2.36 \mathrm{~m})$. Environmental conditions of temperature and humidity were between $17^{\circ} \mathrm{C}-26^{\circ} \mathrm{C}$ and $58 \%-87 \%$, respectively, throughout the whole experiment.

All electrodes were attached once participants were accommodated in a comfortable armchair located $2 \mathrm{~m}$ in front of the screen/television. After sensor attachment, participants were instructed that a series of pictures would appear on the screen/television, they should view each picture for its duration, and they should ignore all sounds that arrived through the headphones.

After psychophysiological recording, participants rated each picture on affective valence and arousal in a free viewing task. For this purpose, participants were provided with the paper-and-pencil version of the Self-Assessment Manikin Questionnaire (SAM; Lang, 1980) and they were instructed in its use. In this task, participants controlled the appearance and disappearance of the pictures by pressing any key on a computer keyboard. To calculate the viewing time of each picture, participants were asked to rate a picture after they had removed it.

\section{Data Reduction and Analysis}

Startle blinks were scored as the magnitude, peak-valley difference $(\mathrm{mV})$, in a 21-120 ms temporary window after the acoustic probe onset. To decrease variability and to establish a common metric across participants, the raw blinks were $z$-score standardized and expressed as $T$-scores $(M=$ $50, S D=10$ ) individually for each participant. For statistical analyses, magnitude was computed as zero in those trials where no response was detected.

Skin conductance response was scored as the largest change (peak-valley difference) above $0.05 \mu$ Siemens occurring in a $0.9-4 \mathrm{~s}$ window following picture onset. All responses lower than $0.05 \mu$ Siemens were computed as zero. To normalize the data, a log transformation ( $\log [\mathrm{SCR}+1])$ was conducted (Venables \& Christie, 1980).

Heart rate was obtained by an off-line transformation of the R-wave, providing a weighted mean of the beat-to-beat HR (Reyes del Paso \& Vila, 1998). Heart rate was averaged off-line into half-second intervals in beats per minute, and then deviated from a 3 -s baseline immediately preceding picture onset. For each participant and each picture, the maximum deceleration in the first $3 \mathrm{~s}$ of picture viewing and the maximum acceleration in the last $3 \mathrm{~s}$ of picture viewing were obtained (Bradley, Codispoti, Cuthbert, et al., 2001; Sánchez-Navarro, Martínez-Selva, \& Román, 2006).

All statistical analyses were performed using the SPSS software. Each measure was analyzed by a mixed model, repeated measures analysis of variance (ANOVA) $2 \times 2 \times 3$ with picture size (large and small) and sex (man and woman) as between-subject variables, and content (unpleasant, neutral and pleasant) as within-subject variable. In addition, trend analyses were performed to assess the effect of the affective valence (linear trend) and the arousal (quadratic trend) on all the measures (Bradley et al., 1990).

All statistical tests used the .05 level of significance. When appropriate, a Grenhouse-Geisser adjustment to the degrees of freedom was used in repeated measures tests in order to correct for any potential inflation of the reported probability values (Bagiella, Sloan, \& Heitjan, 2000), and nominal (unadjusted) degrees of freedom are reported along with epsilon values and the corrected $p$ value. We also estimated the effect size $\left(\eta^{2}\right)$ for both main effects and interactions of content and picture size, as well as the ratios between main factors, that is, the times that content was greater than picture size.

\section{Results}

The means (standard deviations in parentheses) for all responses measured in the study are summarized in Table 1.

Table 1

Response Means (and Standard Deviations) in both Experimental Conditions in Every Picture Valence Category

\begin{tabular}{|c|c|c|c|c|c|c|}
\hline \multirow[b]{3}{*}{ Measurements } & \multicolumn{6}{|c|}{ Picture Size } \\
\hline & \multicolumn{3}{|c|}{ Screen } & \multicolumn{3}{|c|}{ Television } \\
\hline & Unpleasant & Neutral & Pleasant & Unpleasant & Neutral & Pleasant \\
\hline Blink magnitude ( $T$-Score) & $53.33(2.74)$ & $50.25(2.28)$ & $46.42(1.83)$ & $53.23(2.75)$ & $49.28(2.36)$ & $47.50(2.50)$ \\
\hline $\operatorname{SCR}(\log [\mathrm{SCR}+1])$ & $0.113(0.114)$ & $0.057(0.075)$ & $0.102(0.097)$ & $0.085(0.093)$ & $0.037(0.046)$ & $0.082(0.080)$ \\
\hline Initial HR deceleration & $-5.39(2.19)$ & $-4.71(2.03)$ & $-5.23(2.10)$ & $-5.89(1.97)$ & $-4.94(2.01)$ & $-5.65(2.01)$ \\
\hline Final HR acceleration & $3.48(3.69)$ & $3.57(2.36)$ & $2.34(2.53)$ & $2.32(2.88)$ & $4.17(2.28)$ & $2.14(3.41)$ \\
\hline Viewing time (s) & $5.15(2.93)$ & $3.97(1.94)$ & $4.78(2.11)$ & $4.66(2.71)$ & $3.21(1.72)$ & $4.36(2.69)$ \\
\hline Valence rating (SAM) & $2.30(0.87)$ & $5.18(0.59)$ & $7.43(0.95)$ & $2.19(0.70)$ & $4.79(0.99)$ & $7.44(0.84)$ \\
\hline Arousal rating (SAM) & $6.34(1.13)$ & $1.91(1.31)$ & $5.51(1.43)$ & $5.88(1.64)$ & $1.39(0.73)$ & $5.10(1.47)$ \\
\hline
\end{tabular}

Note. SAM = Self-Assessment Manikin Questionnaire (Lang, 1980). 


\section{Startle Blink Response}

A significant main effect was found for content, $F(2$, $106)=56.58, p<.001$; and linear trend, $F(1,53)=105.26$, $p<.001$. The magnitude of this response (see Figure 1) was higher for unpleasant pictures (53.28), followed by neutral (49.79) and pleasant ones (46.93). Single tests showed differences between all types of pictures, pleasant and unpleasant, $t(56)=10.97, p<.001$; unpleasant and neutral, $t(56)=5.77, p<.001 ;$ and pleasant and neutral, $t(56)=$ $5.88, p<.001$. No significant differences or interactions were found in startle blink magnitude for picture size or sex. In this line, the main effect of content was 64.5 times greater than the main effect of picture size (see Table 2).

\section{Table 2}

Statistical Size Effects for the Main Effects and Interactions of the Variables Content and Picture Size

\begin{tabular}{lccc}
\hline & & Effect Size $\left(\eta^{2}\right)$ & Content $\times$ Picture Size \\
\cline { 2 - 4 } Measurements & Content & Picture Size & 0.034 \\
\hline Blink magnitude (T-Score) & 0.516 & 0.008 & 0.007 \\
SCR (Log[SCR+1]) & 0.392 & 0.025 & 0.003 \\
Initial HR deceleration & 0.085 & 0.016 & 0.045 \\
Final HR acceleration & 0.137 & 0.001 & 0.008 \\
Viewing time (s) & 0.305 & 0.014 & 0.022 \\
Valence rating (SAM) & 0.909 & 0.045 & 0.003 \\
Arousal rating (SAM) & 0.803 & 0.047 &
\end{tabular}

Note. SAM = Self-Assessment Manikin Questionnaire (Lang, 1980).
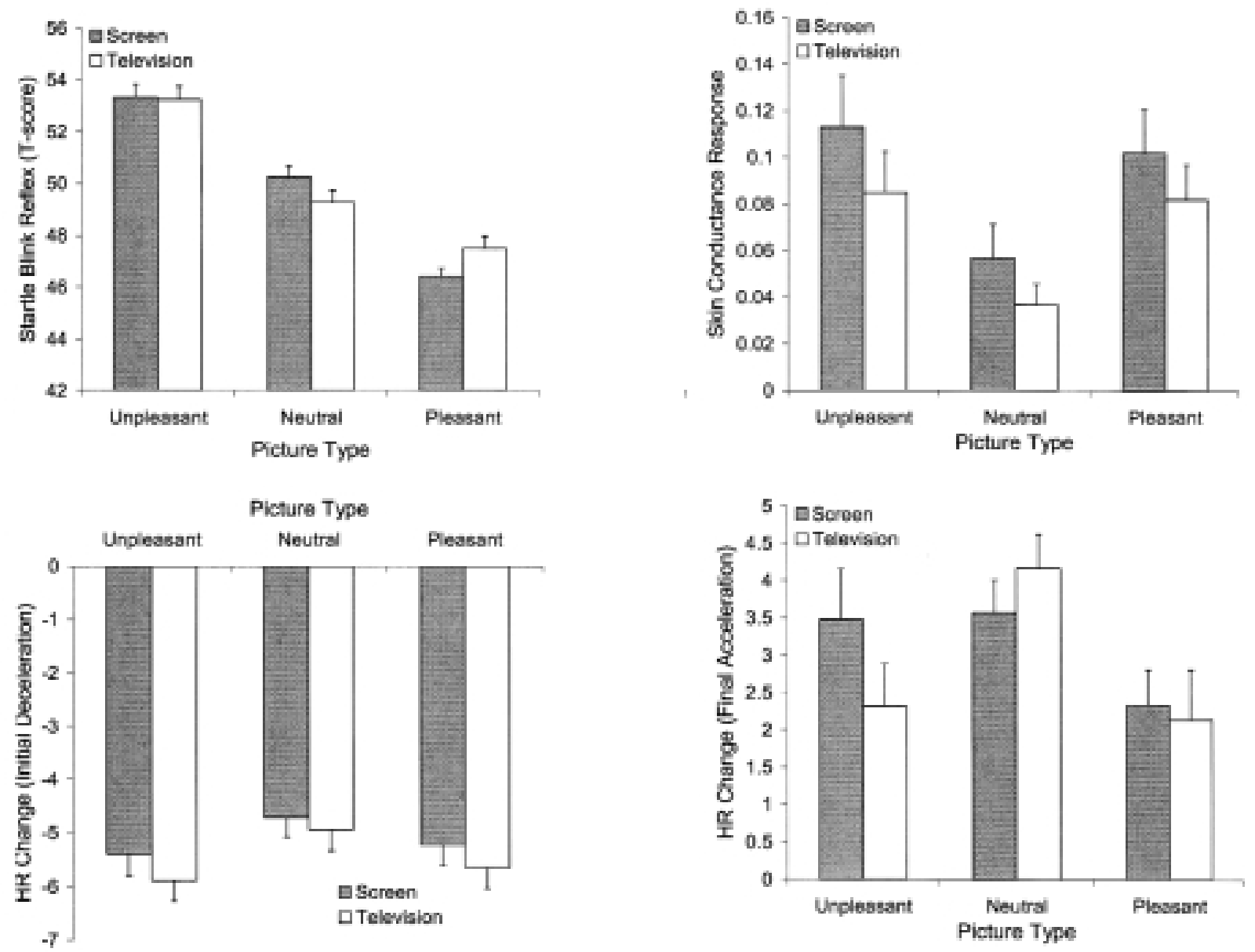

Figure 1. Mean responses in each experimental condition for startle magnitude (top-left), SCR magnitude (top-right), initial heart rate deceleration (bottom-left), and final heart rate acceleration (bottom-right). 


\section{Skin Conductance Response}

We found a significant main effect for content, $F(2,102)$ $=32.91, p<.001$; and quadratic trend, $F(1,51)=54.99, p$ $<.001$. Single tests showed significant differences between pleasant and neutral pictures, $t(54)=7.02, p<.001$; and between unpleasant and neutral ones, $t(54)=6.91, p<.001$; but not between pleasant (0.092) and unpleasant (0.099) pictures (Figure 1). No significant differences or interactions were found in skin conductance response for picture size or sex. As can be seen in Table 2, the main effect of content was 15.68 times greater than the main effect of picture size.

\section{Heart Rate}

Initial HR deceleration. A significant main effect was found for content, $F(2,102)=4.71, p<.05$ (see Figure 1). Trend analysis showed a significant quadratic effect, $F(1$, $51)=7.10, p<.05$. Likewise, single tests showed that there were no significant differences in the HR evoked by pleasant $(-5.43)$ and unpleasant $(-5.63)$ pictures, $\mid t /<1$, and differences appeared only between pleasant and neutral $(-4.82)$ pictures, $t(54)=2.11, p<.05$. Effects or interactions for picture size and sex were not found. As shown in Table 2 , the main effect of content was 5.31 times greater than the main effect of picture size.

Final HR acceleration. A significant main effect was found for content, $F(2,102)=8.10, p<.001$. A significant quadratic trend was also found, $F(1,51)=12.44, p<.001$. Single tests did not show significant differences in the HR acceleration elicited by pleasant (2.24) and unpleasant (2.93) pictures, $t(54)=1.88$, and differences appeared only between unpleasant and neutral (3.85) pictures, $t(54)=2.23, p<.05$. Again, effects or interactions for picture size and sex were not found, and the main effect of content was 137 times greater than the main effect of picture size.

\section{Viewing Time}

The results showed a significant main effect for content, $F(2,114)=25.04, p<.001 ;$ and quadratic effect, $F(1,57)$ $=38.88 ; p<.001$. Participants spent more time viewing both pleasant pictures $(4.57 \mathrm{~s})$ and unpleasant ones (4.91 s), than neutral pictures (3.60 s). Single tests showed significant differences between pleasant and neutral pictures, $t(60)=5.02, p<.001$; and unpleasant and neutral ones, $t(60)=6.29, p<.001$; but not between pleasant and unpleasant pictures, $t(60)=1.88$ (see Table 1). A main effect was also found for sex, $F(1,57)=13.89, p<.001$, with men viewing the pictures for longer periods $(5.64 \mathrm{~s})$ than women $(3.58 \mathrm{~s})$. We did not find significant effects or interactions for picture size. As can be seen in Table 2, the main effect of content was 21.79 times greater than the time effect of picture size.

\section{Affective Valence Ratings}

The analysis of the subjective ratings for the affective picture valence showed a significant main effect for content, $F(2,114)=569.98, p<.001, \in=.819$. Trend analysis showed a linear effect, $F(1,57)=757.25, p<.001$, indicating that pleasant pictures were rated higher (7.44) than neutral (4.99) and unpleasant pictures (2.25). Single tests showed differences between all categories, pleasant and unpleasant, $t(60)=29.31, p<.001$; pleasant and neutral, $t(60)=17.54, p<.001 ;$ and unpleasant and neutral, $t(60)$ $=21.36, p<.001$. Statistical effects or interactions were not found for picture size or sex. The main effect of content was 20.2 times greater than the main effect of picture size (see Table 2).

\section{Arousal Ratings}

A significant main effect was found for content, $F(2$, $114)=232.77, p<.001$. Trend analysis showed a linear effect, $F(1,57)=10.40, p<.01$, and a quadratic one, $F(1$, $57)=404.32, p<.001$. The quadratic effect indicated that participants rated both pleasant (5.31) and unpleasant (6.11) pictures with higher arousal than neutral pictures (1.65), whereas the linear effect indicated that differences also existed between pleasant and unpleasant pictures (see Table 1). However, we also found an interaction effect between sex and content, $F(2,114)=3.87, p<.05$. In men, a significant effect for content was found, $F(2,44)=81.39$, $p<.001$; and quadratic trend, $F(1,22)=126.10, p<.001$. Pleasant (5.85) and unpleasant (5.89) pictures were rated with higher arousal than neutral ones (1.80). Women's ratings showed a significant main effect for content, $F(2,74)=$ $178.51, p<.001$, and the trend analysis revealed a linear effect, $F(1,37)=25.03, p<.001$; and a quadratic one, $F(1$, $37)=325.59, p<.001$. This indicated that women rated unpleasant pictures (6.25) with the highest arousal, followed by pleasant (4.98) and then neutral ones (1.57). Lastly, there were no significant effects or interactions for picture size, and the main effect of content was 17.09 greater than the main effect of picture size (Table 2).

\section{Discussion}

The aim of our study was to assess whether psychophysiological, behavioral and cognitive indices of the emotional responses depended on the affective content of the emotional stimuli or, in contrast, whether the size of the stimuli exerted some influence on the emotional responses. We found no differences depending on the size of the emotional pictures in any index under study.

The magnitude of the blink response was similar under both experimental conditions. Independently of size, blink response showed a pattern of emotional modulation 
characterized by enhancement for unpleasant pictures and inhibition for pleasant ones. These data replicate the results obtained in previous research, indicating a blink response modulation caused by the affective content of the stimuli (e.g., Bradley et al., 1990; Vrana et al., 1988). Hence, the pattern of emotional modulation of the blink response was not affected by picture size, but by its content, replicating previous results (e.g., Bradley, Codispoti, Cuthbert, et al., 2001; Martínez-Selva, Román, \& Sánchez-Navarro, 2001). As emotional modulation of the startle reflex has been proved to be a reliable measurement of the valence component of the emotion, this result could have an important repercussion on communication, persuasion, and advertisement research, because it shows that emotional response depends on the content of the message and not on its form.

Unpleasant and pleasant pictures evoked higher SCRs than did neutral ones, that is, pictures with the highest arousal ratings evoked the greatest SCRs. However, we did not find an effect of picture size on SCR, in contrast to the results obtained by Reeves et al. (1999), who found an image size effect on this autonomic response. These authors concluded that large size could increase arousal and attention to the picture message. In addition, Reeves et al. (1999) also found that large screens increased arousal when the pictures had a high arousing potential. Again, our data do not support their results. This discrepancy between our results and those of Reeves et al. could be explained by several factors. First, the experimental designs differed, because these authors included motion pictures, which have a clear effect on the emotional response (e.g., Simons et al., 1999), whereas we studied only still pictures. Second, they did not report data on SCRs, but on skin conductance levels (SCLs), whereas we recorded the response elicited by the pictures.

Likewise, we did not find differences depending on the picture size in the HR change, as we obtained both a similar initial HR deceleration and final HR acceleration under both experimental conditions. These results are also in contrast to those found by Reeves et al. (1999). Several explanations could clarify these differences between the studies, in addition to the different experimental design as mentioned above. Although these authors indicated a size effect on the HR deceleration elicited by the stimuli, a closer examination of the values that they report does not appear to indicate an emotional effect, because they do not report differences in HR deceleration depending on the affective valence or arousal in function of the stimuli size. However, in line with previous research (e.g., Sánchez-Navarro et al., 2005), we found that HR changes depended on the arousal of the pictures. High arousal pictures (unpleasant and pleasant) promoted both greater initial deceleration and greater final acceleration than did non-arousing pictures (neutral). This result shows a pattern of response that depends more on the emotional arousal of the stimuli than on their affective content, in contrast to the results found in other studies (Bradley et al., 1990; Bradley, Codispoti, Cuthbert, et al., 2001; Greenwald et al., 1989;
Lang et al., 1993). This result also appeared in the free viewing time task, with participants spending longer times for pleasant and unpleasant pictures than for neutral ones. Hence, our results showed that participants paid more attention to the arousing and more interesting stimuli than to the less arousing and less interesting ones, as previous research has shown (Bradley, 2000; Lang et al., 1993), and this was independent of the picture size.

Affective valence and arousal ratings of the pictures did not depend on picture size, but showed different patterns for men and women. Whereas men rated pleasant and unpleasant pictures with the highest arousal level, women rated unpleasant pictures with higher arousal than pleasant ones and these, in turn, were higher than the neutral ones. Our data are in agreement with those from previous research (e.g., Bradley, Codispoti, Sabatinelli, \& Lang., 2001) showing that women rate unpleasant stimuli as more arousing than men. In this line, unpleasant pictures appear to elicit a greater defensive activation in women, and this tendency could, at least partially, be biologically determined (Bradley et al., 2001).

Our results on the subjective ratings of arousal are also in contrast to the data reported by Detenber and Reeves (1996) and Reeves et al. (1999), who found that participants rated large pictures as more arousing than small pictures. Detenber and Reeves (1996) indicated that large pictures evoke a higher arousal feeling than small pictures, and they explained this effect by the fact that large pictures constituted more compelling and significant stimuli. However, our results do not support this view, and indicate that the size of the pictures has no effect on the emotional responses they prompt, but that their content is the most important property in eliciting this response, as found by other studies which varied the formal properties of the same stimuli and obtained a similar response (e.g., Bradley, Codispoti, Cuthbert, et al., 2001).

The results of this research have important implications for visual-based techniques used in communication research, pointing to the content of the image as the determining element of the physiological changes it elicits, the cognitive processing it demands, and the behavioral action that it prompts. Our data, therefore, indicate that the emotional response elicited by pictures does not depend on their size but on their content.

In conclusion, our data are in accordance with a motivational model, which defines emotion as a preparation/trend to action (Lang, 1994, 1995). Emotion, therefore, would reflect the performance of two motivational basic systems - appetitive and aversive - which vary in their activation level (Lang, Bradley, \& Cuthbert, 1998). Hence, following the results obtained in this study and those by Bradley, Codispoti, Cuthbert, et al. (2001) referring to the color of the affective pictures, we can state that emotional responses depend on the content of the affective pictures, which activate these two motivational systems, and do not show a relationship with the medium employed to display them. 


\section{References}

Bagiella, E., Sloan, R.P., \& Heitjan, D.F. (2000). Mixed-effects models in psychophysiology. Psychophysiology, 37, 13-20.

Bradley, M.M. (2000). Emotion and motivation. In J.T. Cacioppo, L.G. Tassinary, \& G.G. Bernston (Eds.), Handbook of psychophysiology ( $2^{\text {nd }}$ ed, pp. 602-642). Cambridge: Cambridge University Press.

Bradley, M.M., Codispoti, M., Cuthbert, B.N., \& Lang, P.J. (2001). Emotion and motivation I: Defensive and appetitive reactions in picture processing. Emotion, 1, 276-298.

Bradley, M.M., Codispoti, M., Sabatinelli, D. \& Lang, P.J. (2001). Emotion and motivation II: Sex differences in picture processing. Emotion, 1, 300-319.

Bradley, M.M., Cuthbert, B.N., \& Lang, P.J. (1990). Startle reflex modification: Emotion or attention? Psychophysiology, 27, 513522.

Cacioppo, J.T., \& Sandman, C.A. (1981). Psychophysiological functioning, cognitive responding, and attitudes. In R.E. Petty, T.M. Ostrom, \& T.C. Brock (Eds.), Cognitive responses in persuasion (pp. 81-104). Hillsdale, NJ: Erlbaum.

Center for the Study of Emotion and Attention [CESEA-NIHM] (1999). The International Affective Picture System: Digitized photographs. Gainesville, FL: The Center for Research in Psychophysiology, University of Florida.

Christie, I.C., \& Friedman, B.H. (2004). Autonomic specificity of discrete emotion and dimensions of affective space: A multivariate approach. International Journal of Psychophysiology, 51, 143153.

Cuthbert, B.N., Bradley, M.M., \& Lang, P.J. (1996). Probing picture perception: Activation or emotion. Psychophysiology, 33, 103-111.

Detenber, B.H., \& Reeves, B. (1996). A bio-informational theory of emotion: Motion and image size effects on viewers. Journal of Communication, 46, 66-84.

Fowles, D.C., Christie, M.J., Edelberg, R., Grings, W.W., Lykken, D.T., \& Venables, P.H. (1981). Publication recommendations for electrodermal measurements. Psychophysiology, 18, 232-239.

Fridlund, A.J., \& Cacioppo, J.T. (1986). Guidelines for human electromyographic research. Psychophysiology, 23, 567-589.

Globisch, J., Hamm, A.O., Esteves, F., \& Öhman, A. (1999). Fear appears fast: Temporal course of startle reflex potentiation in animal fearful subjects. Psychophysiology, 36, 66-75.

Gomez, P., Zimmermann, P., Guttormsen-Schär, S., \& Danuser, B. (2005). Respiratory responses associated with affective processing of film stimuli. Biological Psychology, 68, 223-235.

Greenwald, M.K., Cook, E.W., \& Lang, P.J. (1989). Affective judgment and psychophysiological response: Dimensional covariation in the evaluation of pictorial stimuli. Journal of Psychophysiology, 3, 51-64.

Grimshaw, G.M., Bulman-Fleming, M.B., \& Ngo, C. (2004). A signal-detection analysis of sex differences in the perception of emotional faces. Brain and Cognition, 54, 248-250.

Jansen, D.M., \& Frijda, N.H. (1994). Modulation of the acoustic startle response by film-induced fear and sexual arousal. Psychophysiology, 31, 565-571.
Lang, P.J. (1968). Fear reduction and fear behavior: Problems in treating a construct. In J. Schlien (Ed.), Research in psychotherapy (Vol. 3, pp. 205-227). Washington: American Psychological Association.

Lang, P.J. (1980). Behavioral treatment and bio-behavioral assessment: Computer applications. In J.B., Sidowski, J.H. Johnson, \& T.A. Williams (Eds.), Technology in mental health care delivery systems (pp. 119-137). Norwood: Ablex.

Lang, P.J. (1984). Cognition in emotion: Concept and action. In C.E. Izard, J. Kagan, \& R.B. Zajonc (Eds.), Emotions, cognition, and behavior (pp. 198-228). New York: Cambridge University Press.

Lang, P.J. (1994). The motivational organization of emotion: Affectreflex connections. In S.H.M. Van Goozen, N.E. Van de Poll, \& J.A. Sergeant (Eds.), Emotions: Essays on emotion theory (pp. 61-93). Hillsdale, NJ: Erlbaum.

Lang, P.J. (1995). The emotion probe. American Psychologist, 50, 372-385.

Lang, P.J., Bradley, M.M., \& Cuthbert, B.N. (1998). Emotion, motivation, and anxiety: Brain mechanisms and psychophysiology. Biological Psychiatry, 44, 1248-1263.

Lang, P.J., Greenwald, M.K., Bradley, M.M., \& Hamm, A.O. (1993). Looking at pictures: Affective, facial, visceral, and behavior reactions. Psychophysiology, 30, 261-273.

Larson, C.L., Ruffalo, D., Nietert, J.Y., \& Davidson, R.J. (2000). Temporal stability of the emotion-modulated startle response. Psychophysiology, 37, 92-101.

Martínez-Selva, J.M., Román, F., \& Sánchez-Navarro, J.P. (2001, May-June). Modulation of the eyeblink startle reflex and stimulus size. Communication presented at the II International Workshop on Emotion and the Brain, Palma de Mallorca, Spain.

Moltó, J., Montañés, S., Poy, R., Segarra, P., Pastor, M.C., Tormo, M.P., Ramírez, I., Hernández, M.A., Sánchez, M., Fernández, M.C., \& Vila, J. (1999). Un nuevo método para el estudio experimental de las emociones: El International Affective Picture System (IAPS). Adaptación española. Revista de Psicología General y Aplicada, 52, 55-87.

Mühlberger, A., Herrmann, M.J., Wiedemann, G., Ellgring, H., \& Pauli, P. (2001). Repeated exposure of flight phobics to flights in virtual reality. Behaviour Research and Therapy, 39, 1033-1050.

Reeves, B., Lang, A., Kim, E.Y., \& Tatar, D. (1999). The effects of screen size and message content on attention and arousal. Media Psychology, 1, 49-67.

Reyes del Paso, G.A., \& Vila, J. (1998). The continuing problem of incorrect heart rate estimation in psychophysiological studies: An off-line solution for cardiotachometer users. Biological Psychology, 48, 269-279.

Rossignol, M., Philippot, P., Douilliez, C., Crommelinck, M., \& Campanella, S. (2005). The perception of fearful and happy facial expression is modulated by anxiety: An event-related potential study. Neuroscience Letters, 377, 115-120.

Sánchez-Navarro, J.P., Martínez-Selva, J.M., \& Román, F. (2005). Emotional response in patients with frontal brain damage: Effects of the affective valence and information content. Behavioral Neuroscience, 119, 87-97. 
Sánchez-Navarro, J.P., Martínez-Selva, J.M., \& Román, F. (2006). Uncovering the relationship between defence and orienting in emotion: cardiac reactivity to unpleasant pictures. International Journal of Psychophysiology, 61, 34-46.

Simons, R.F., Detenber, B.H., Reiss, J.E., \& Shults, C.W. (2000). Image motion and context: A between- and within-subjects comparison. Psychophysiology, 37, 706-710.

Simons, R.F., Detenber, B.H., Roedema, T.M., \& Reiss, J.E. (1999). Emotion processing in three systems: The medium and the message. Psychophysiology, 36, 619-627.

Venables, P.H., \& Christie, M.J. (1980). Electrodermal activity. In I. Martin \& P.H. Venables (Eds.), Techniques in psychophysiology (pp. 4-67). New York: Wiley.

Vila, J., Fernández, M.C., Pegalajar, J., Vera, M.N., Robles, H., Pérez, N., Sánchez, M.B., Ramírez, I., \& Ruíz-Padial, E. (2003). A new look at cardiac defense: Attention or emotion? The Spanish Journal of Psychology, 6, 60-78.
Vila, J., Sánchez, M., Ramírez, I., Fernández, M.C., Cobos, P., Rodríguez, S., Muñoz, M.A., Tormo, M.P., Herrero, M., Segarra, P., Pastor, M.C., Montañés, S., Poy, R., \& Moltó, J. (2001). El sistema internacional de imágenes afectivas (IAPS): Adaptación española. Segunda parte. Revista de Psicología General y Aplicada, 54, 635-657.

Vrana, S.R., Spence, E.L., \& Lang, P.J. (1988). The startle probe response: A new measure of emotion? Journal of Abnormal Psychology, 97, 487-491.

Wald, J., \& Taylor, S. (2000). Efficacy of virtual reality exposure therapy to treat driving phobia: A case report. Journal of Behaviour Therapy and Experimental Psychiatry, 31, 249257.

Received January 30, 2006 Review received July 30, 2006

Accepted August 1, 2006 